\title{
Fabrication of Ti-6Al-4V Scaffolds by Direct Metal Deposition
}

\author{
G.P. DINDA, L. SONG, and J. MAZUMDER
}

\begin{abstract}
Direct metal deposition (DMD) is a rapid laser-aided deposition method that can be used to manufacture near-net-shape components from their computer aided design (CAD) files. The method can be used to produce fully dense or porous metallic parts. The Ti-6Al-4V alloy is widely used as an implantable material mainly in the application of orthopedic prostheses because of its high strength, low elastic modulus, excellent corrosion resistance, and good biocompatibility. In the present study, Ti-6Al-4V scaffold has been fabricated by DMD technology for patient specific bone tissue engineering. Good geometry control and surface finish have been achieved. The structure and properties of the scaffolds were investigated by X-ray diffraction (XRD), scanning electron microscopy (SEM), transmission electron microscopy (TEM), and tension test. The microstructures of laser-deposited Ti-6Al-4V scaffolds are fine Widmanstätten in nature. The tensile and yield strengths of the as-deposited Ti-6Al-4V were $1163 \pm 22$ and $1105 \pm 19 \mathrm{MPa}$, respectively, which are quite higher than the ASTM limits (896 and $827 \mathrm{MPa}$ ) for Ti-6Al-4V implants. However, the ductility of the as-deposited sample was very low $(\sim 4 \mathrm{pct})$, which is well below the ASTM limit $(10 \mathrm{pct})$. After an additional heat treatment (sample annealed at $950{ }^{\circ} \mathrm{C}$ followed by furnace cooling), both strength (UTS $1045 \pm 16$, and $\mathrm{YS} \sim 959 \pm 12 \mathrm{MPa})$ and ductility $(\sim 10.5 \pm 1 \mathrm{pct})$ become higher than ASTM limits for medical implants.
\end{abstract}

DOI: $10.1007 / \mathrm{s} 11661-008-9634-\mathrm{y}$

(C) The Minerals, Metals \& Materials Society and ASM International 2008

\section{INTRODUCTION}

TISSUE engineering constitutes a promisingly alternative approach to the repair of damaged tissue or organs. Different biomaterials have been used as scaffolds, including bioactive metallic, ${ }^{[1]}$ ceramics, ${ }^{[2]}$ and polymers $^{[3]}$ for bone tissue engineering. Ideally, the materials should exhibit adequate mechanical and biological properties. The primary roles of scaffold are (1) to serve as an adhesion substrate for the cell, facilitating the localization and delivery of cells when they are implanted; (2) to provide temporary mechanical support to the newly grown tissue; and (3) to guide the development of new tissues with the appropriate function. Moreover, the scaffold should be biocompatible. A titanium alloy, specifically Ti-6Al-4V, is widely used as an implant material for biomedical applications due to its relatively low modulus, good biocompatibility, and enhanced corrosion resistance when compared to more conventional stainless steels and cobalt-based alloys. The principal focus of this study is to produce ideal scaffolds of Ti-6Al-4V by the direct metal deposition (DMD) technique for patient specific bone tissue engineering with good mechanical and metallurgical properties.

Rapid prototyping, also known as solid freeform fabrication, is a manufacturing process that quickly produces physical prototypes directly from computer

G.P. DINDA, Research Fellow, L. SONG, Research Investigator, and J. MAZUMDER, Professor, are with the Department of Mechanical Engineering, University of Michigan, Ann Arbor, MI 48109. Contact e-mail: dinda@umich.edu

Manuscript submitted April 16, 2007.

Article published online September 17, 2008 aided design (CAD) solid models using a special class of fabrication technology. Direct laser deposition is a rapid prototyping method that can be used to manufacture near-net-shape components from their CAD files in one step. The $\mathrm{DMD}^{[4,5]}$ technology developed at the University of Michigan, direct light fabrication (DLF) ${ }^{[6,7]}$ developed at the Los Alamos National Laboratories, and laser engineering net shaping (LENS $)^{[8,9]}$ developed at the Sandia National Laboratories in the early 1990s are all successful examples of direct laser deposition technology. The basic principles of DMD, DLF, and LENS processes are similar in that they use a focused laser beam as a heat source to melt metallic powder and create a three-dimensional (3-D) object. In addition, the DMD and LENS have a feedback control system that provides a closed-loop control of dimension during the deposition process. In the present investigation, the DMD system developed at the University of Michigan was used to fabricate complex shaped metallic scaffolds for medical implants, which are very difficult to process for conventional methods.

First, the CAD model of the component is sliced into a series of parallel layers with a certain build-height. During the DMD process, powder is fed at a controlled rate into the focal point of a high-power laser where the individual particles are melted. The CAD files control both movements of substrate in the $X-Y$ plane and laser beam in the $Z$ direction to add successive layers, thus directly generating a three-dimensional component without the necessity of any machining. There are many variables in this process that can affect the material properties and the microstructure of the resulting part, such as laser power, powder feed rate, and laser scanning speed. 
The aim of the present work is to produce ideal Ti-6Al-4V scaffolds and to study the microstructural development and mechanical response for their applicability as hard tissue biomaterials.

\section{EXPERIMENTAL PROCEDURE}

\section{A. Materials}

Gas-atomized prealloyed Ti-6Al-4V powder $(-100+$ 325 mesh, Starmet Inc., Concord, MA) was used to fabricate 3-D scaffold. The powder had a composition (in wt pet) of 5.99 aluminum, 4.02 vanadium, 0.21 iron, 0.19 oxygen, 0.04 carbon, 0.02 nitrogen, 0.04 silicon, and balance titanium. Figure 1 shows that the as-received powder particles are rather spherical. Quantitative analysis of the SEM images of about 100 powder particles, measuring always the largest diameter and the diameter in the direction perpendicular to the long axis, showed that the mean particle size is about $84 \mu \mathrm{m}$, whereas 82 pct of the powder particles are in the range between 60 and $120 \mu \mathrm{m}$.

\section{B. Scaffold Fabrication}

There are five primary components of the DMD assembly: the laser system, the powder delivery system, sensors for feedback loop for dimension control, the controlled environment, and the CAD driven motion control system. ${ }^{[10]}$ A sketch of the DMD system is shown in Figure 2. A $6 \mathrm{KW} \mathrm{CO}_{2}$ laser unit was used in the present experiment. The laser processing parameters used were as follows: laser scanning speed, $36.6 \mathrm{~mm} \mathrm{~min}^{-1}$; powder feed rate, $5 \mathrm{~g} \mathrm{~min}^{-1}$; and $Z$ increment, $0.25 \mathrm{~mm}$. The scaffold was fabricated on a substrate of Ti-6Al-4V rolled plate. During DMD processing, $300 \mathrm{~W}$ laser beam was focused on the substrate to create a melt pool into which the powder feedstock is delivered through an inert gas $(\mathrm{He})$ flowing through a special nozzle, where the powder streams converge at the same point on the focused laser beam (beam diameter $=0.5 \mathrm{~mm}$ ). An inert gas shroud

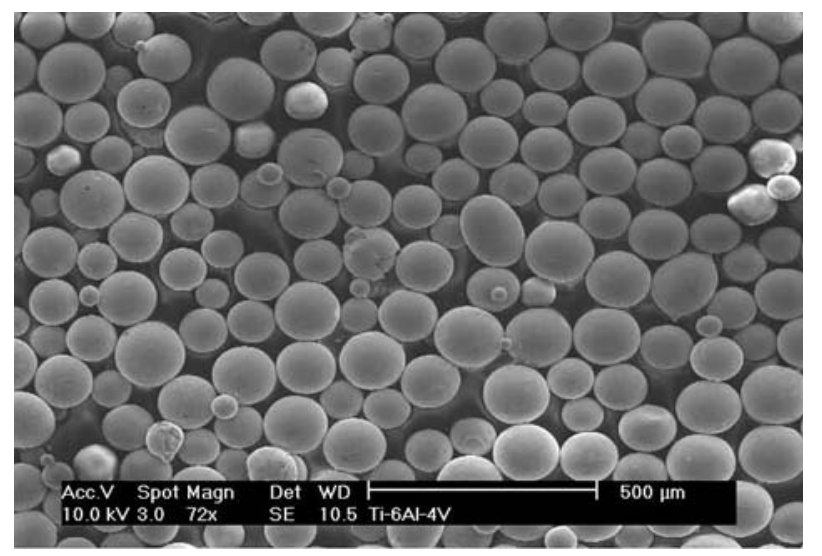

Fig. 1-Morphology of the as-received Ti-6Al-4V prealloyed powder.

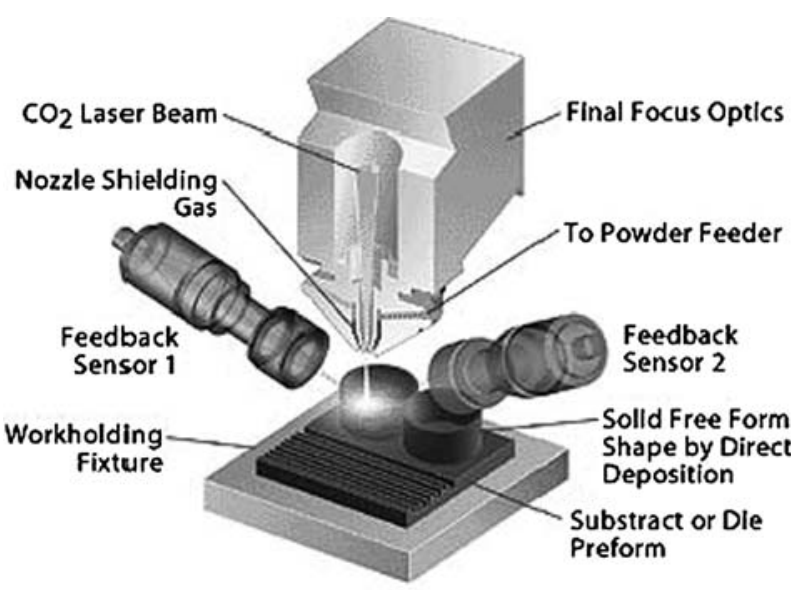

Fig. 2-Schematic description of the DMD system.
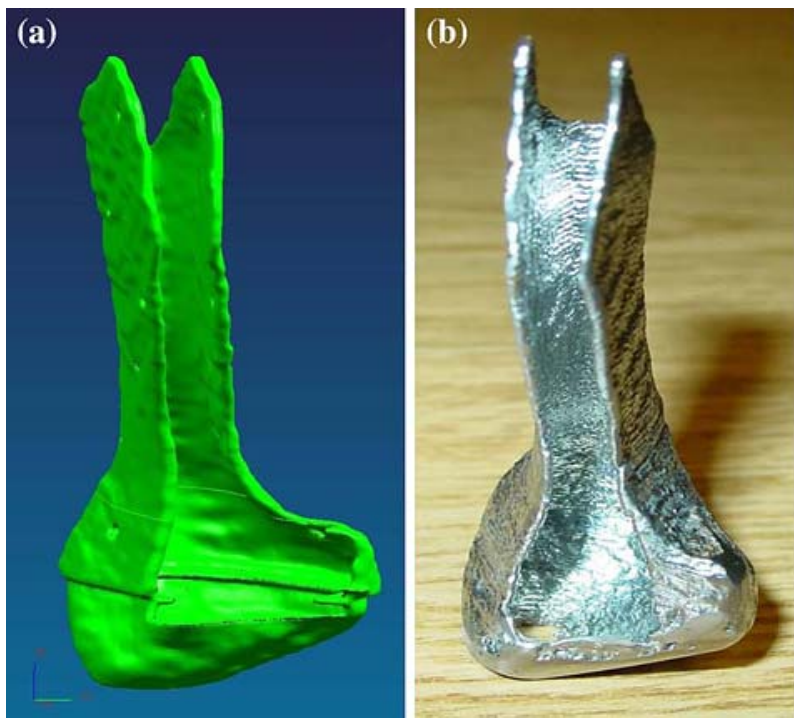

Fig. 3- (a) CAD image of the CRU of a Yucatan minipig. (b) An identical Ti-6Al-4V scaffold was produced by the DMD process.

containing a mixture of helium and argon was used as a protective atmosphere for preventing oxidation during deposition. No feedback control system was used in the present experiment. Without any feedback control, several identical scaffolds were successfully fabricated after subsequent layers deposition (Figure 3).

For mechanical tests, tensile specimens were fabricated according to the ASTM E 8 standard (gage length: $25 \mathrm{~mm}$, width: $6.25 \mathrm{~mm}$, and thickness: $0.7 \mathrm{~mm}$ ) by the same laser deposition parameters that have used for scaffold fabrication. The specimens were then polished using different (240 to 1200 ) emery papers to improve the surface smoothness for the tension test. The tensile axis of all specimens was perpendicular to the deposit direction. The tensile specimens were tested in a universal testing machine (Instron 55005) at a crosshead speed of $0.5 \mathrm{~mm} \mathrm{~min}^{-1}$. Three tests were conducted for each condition to ensure the reproducibility of the results. It should be mentioned that tensile fracture occurred near the middle of the gage section. 
In order to improve the ductility of the laser-deposited samples, several tensile specimens were annealed at $950{ }^{\circ} \mathrm{C}$ and $1050{ }^{\circ} \mathrm{C}$ followed by either air cooling (AC) or furnace cooling (FC). The heat treatment was performed in a horizontal cylindrical furnace under an argon atmosphere for 1 hour.

\section{Characterization}

The microstructures of the laser-deposited scaffold were investigated by optical microscopy (OM) (Nikon eclipse ME600), scanning electron microscopy (SEM, PHILIPS* XL30 FEG scanning electron

*PHILIPS is a trademark of Philips Electronic Instruments Corp., Mahwah, NJ.

microscope), and transmission electron microscopy (TEM, JEOL** 2010 transmission electron microscope

**JEOL is a trademark of Japan Electron Optics Ltd., Tokyo.

operating at $200 \mathrm{kV}$ ). The as-deposited samples were investigated using X-ray diffraction (Rigaku rotating anode XRD) with $\mathrm{Cu} K_{\alpha}$ radiation. Specimens for OM and SEM were cut out from different parts of the scaffold. A Kroll's (10 mL $\mathrm{HNO}_{3}, 5 \mathrm{~mL} \mathrm{HF}$, and $85 \mathrm{~mL}$ $\mathrm{H}_{2} \mathrm{O}$ ) etchant was used for the OM and SEM. For transmission electron microscopy/selected area electron diffraction (TEM/SAD), $3 \mathrm{~mm}$ in diameter samples were mechanically punched out. Thereafter, the samples were thinned by ion milling with low accelerating voltage $(3.5 \mathrm{kV})$ to minimize the beam effects on the microstructure.

The surface roughness of the DMD samples parallel to the build direction was measured over a length of $3 \mathrm{~mm}$ using a stylus profilometer (Form Talysurf 50, Taylor-Hobson). The roughness value was calculated by averaging the data from five measurements.

\section{RESULTS}

\section{A. Surface Morphology}

Figure 3(a) shows an image of the condylar ramus unit (CRU) of a Yucatan minipig. The image of the CRU was designed using a computed tomography (CT) scan on a 6-month-old Yucatan minipig. A detailed description of the CRU scaffold design technique may be found elsewhere. ${ }^{[1]}$ Several identical Ti-6Al-4V scaffolds for the porcine CRU bone tissue engineering were successfully manufactured by DMD (Figure 3(b)). However, the surface of the as-fabricated scaffold was relatively rough. Many granular particles were associated with the surface. However, with regard to the proposed use of scaffold, the surface particles in vivo would probably cause inflammation due to the macrophase activation. In order to remove the unwanted particles from the surface, a sandblasting operation was
Table I. Surface Roughness of the As-Deposited Ti-6Al-4V Scaffold after Sand Blasting and Chemical Etching

\begin{tabular}{lccc}
\hline Roughness & As-Deposited & $\begin{array}{c}\text { Sand } \\
\text { Blasted }\end{array}$ & Etched \\
\hline$R a$ (average roughness) & $25 \mu \mathrm{m}$ & $12 \mu \mathrm{m}$ & $8 \mu \mathrm{m}$ \\
$R q$ (root-mean-square & $31 \mu \mathrm{m}$ & $16 \mu \mathrm{m}$ & $12 \mu \mathrm{m}$ \\
$\begin{array}{l}\text { roughness ) } \\
R t \text { (maximum peak-to-valley } \\
\text { height) }\end{array}$ & $146 \mu \mathrm{m}$ & $73 \mu \mathrm{m}$ & $49 \mu \mathrm{m}$ \\
\hline
\end{tabular}

performed on the surface of the scaffold. The particle layer was removed from the surface after sandblasting. To further improve the surface quality, the sandblasted scaffold was chemically polished by a Kroll's reagent $\left(10 \mathrm{~mL} \mathrm{HNO}_{3}, 5 \mathrm{~mL} \mathrm{HF}\right.$, and $85 \mathrm{~mL}$ water) for 5 minutes. The surface becomes very smooth (Table I) after optimal chemical polishing. The average surface roughness $\left(R_{a}\right)$ reduces to $8 \mu \mathrm{m}$ after chemical etching. The roughnesses of the as-deposited and sand-blasted scaffold were 25 and $12 \mu \mathrm{m}$, respectively.

Figure 4(a) shows an SEM image of the as-deposited scaffold surface. Many spherical particles, which had diameters from 50 to $120 \mu \mathrm{m}$, were associated with the surface. It was observed that the associated surface particles are spherical in shape and the particle size distribution is very close to that of the as-received powder particles. It should be noted that the surface particles are the excess unmelted powder particles. It can be seen from Figure 4(b) that the surface of the scaffold after sandblasting operation is free from particles. However, the surface becomes relatively rough due to the sandblasting operation. Finally, Figure 4(c) shows the rough sandblasted surface becoming smooth after an additional chemical etching by Kroll's reagent for 5 minutes.

\section{B. XRD Analysis}

Figure 5 shows the XRD scan of Ti-6Al-4V scaffold produced by DMD. The equilibrium microstructure at room temperature of Ti-6Al-4V alloy is a mixture of $\alpha$ (hcp) and $\beta$ (bcc) phases. However, the nature of the $\alpha$ phase, whether it will be martensite or diffusion-controlled Widmastätten structure, varies based on the thermal history of the alloy. The XRD scan (Figure 5) shows that the Bragg peaks belong to either $\alpha$ or $\beta$ phase. No other phase has been observed in the XRD scan.

\section{Microstructure}

\section{Optical microscopy}

Figure 6 shows typical optical micrographs of the as-deposited scaffold. It should be noted that the prior $\beta$ grains were columnar in nature. The axes of the columnar grains are approximately parallel to the $Z$-axis, i.e., the build direction of the deposit (Figure 6(a)). The width of columnar grains varies from 0.15 to $0.8 \mathrm{~mm}$, whereas the average width of the columnar grains is around $0.3 \mathrm{~mm}$. In addition to the columnar grain structure, a periodically bandlike struc- 

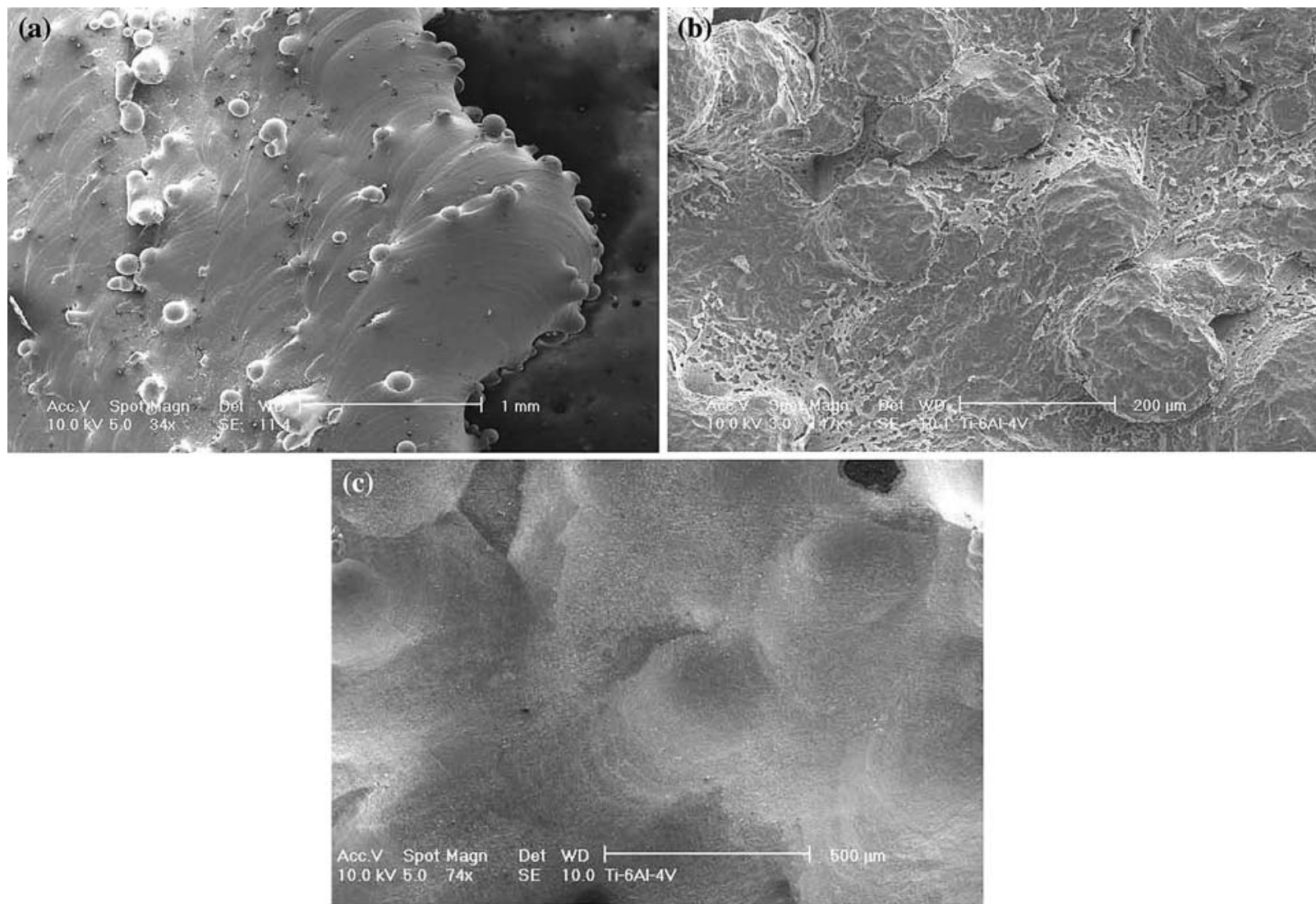

Fig. 4 -SEM micrographs of (a) the as-fabricated scaffold surface (50 to $120 \mu \mathrm{m}$ spherical particles were observed at the surface), $(b)$ the sandblasted scaffold surface, and $(c)$ the surface after chemical etching.

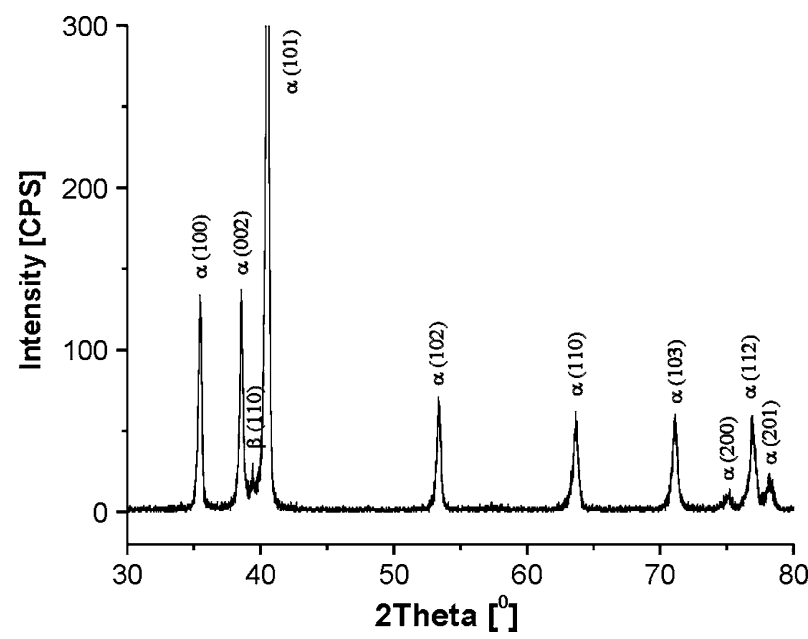

Fig. 5-XRD scan of as-deposited Ti-6Al-4Vscaffold.

ture was observed in the optical micrograph (Figure 6(a)). The thickness of the band is $\sim 0.25 \mathrm{~mm}$, which is basically the thickness of each deposited layer. However, the microstructures within the prior $\beta$ grains were fine Widmanstätten in nature (Figure 6(b)) with very fine $\alpha$ grains distributed both within the prior $\beta$ grains and along the grain boundaries.

\section{Scanning electron microscopy}

The SEM micrographs (Figure 7) of the as-deposited scaffold clearly show that the observed microstructures are Widmanstätten in nature. In addition to the Widmanstätten $\alpha$ laths, Figures 7(b) and (d) also show that the prior $\beta$ grain boundaries are decorated with $\alpha$. Moreover, the size and distribution of $\alpha$ laths varies at different locations of the sample. For example, Figures 7(a) and (b) show the typical Widmanstätten lathlike morphology with a relatively large aspect ratio. Furthermore, the microstructure consists of intricately mixed multiple variants of $\alpha$ laths, often referred to as the basketweave microstructure, whereas Figure 7(d) shows more equiaxed-like morphology with a smaller aspect ratio of $\alpha$ laths. In addition, Figure 7(c) shows both fine (center part of the figure) and relatively coarse (top and bottom parts) Widmanstätten $\alpha$ laths.

\section{Transmission electron microscopy}

Figure 8 shows TEM micrographs of the as-deposited Ti-6Al-4V scaffold. The bright-field TEM image (Figure 8(a)) of the as-deposited scaffold confirms the observation of the scanning electron microscopy that the microstructure consists of fine Widmanstätten $\alpha$. A selected area electron diffraction pattern (Figure $8(\mathrm{~b})$ ) of Figure 8(a) further confirmed the presence of $\alpha$ (hcp) phase in the microstructure. In addition to the Widmanstätten $\alpha$ formation in the as-deposited Ti-6Al-4V, 


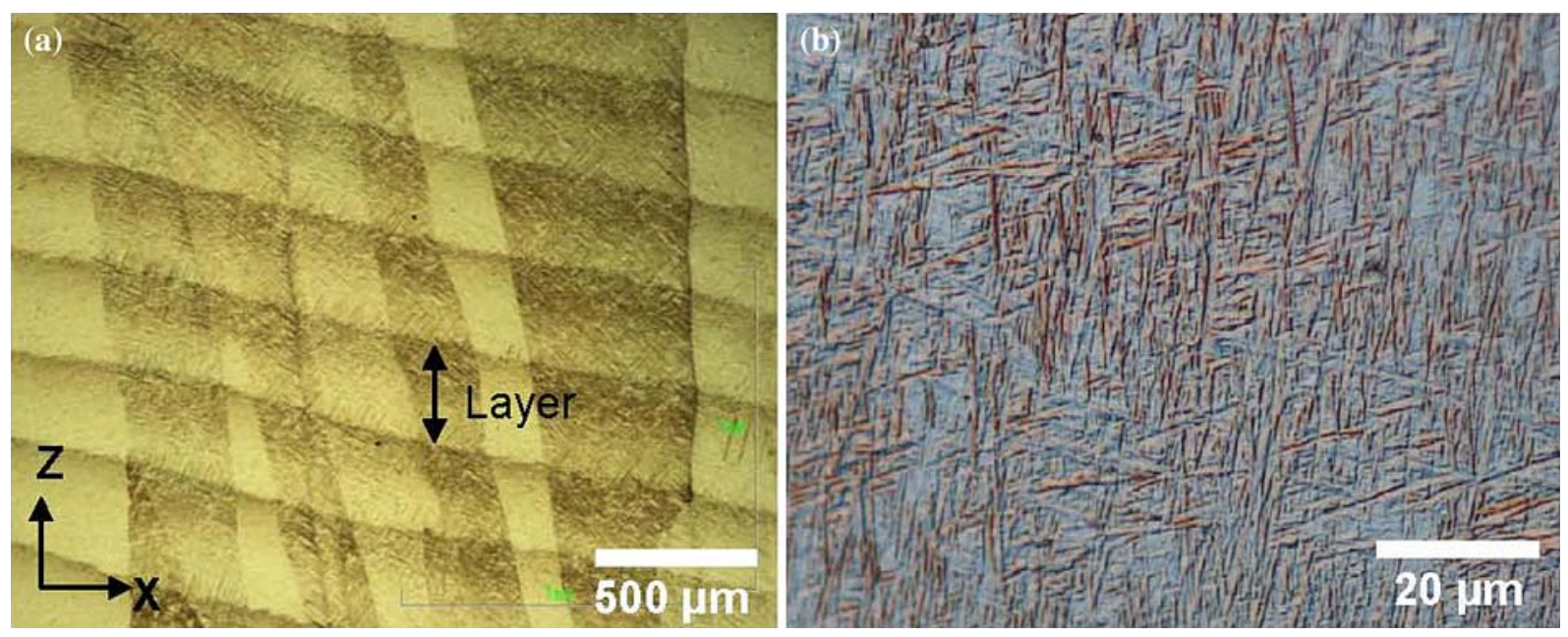

Fig. 6-Optical micrographs of as-deposited scaffold showing (a) columnar grains and (b) Widmanstätten structure.
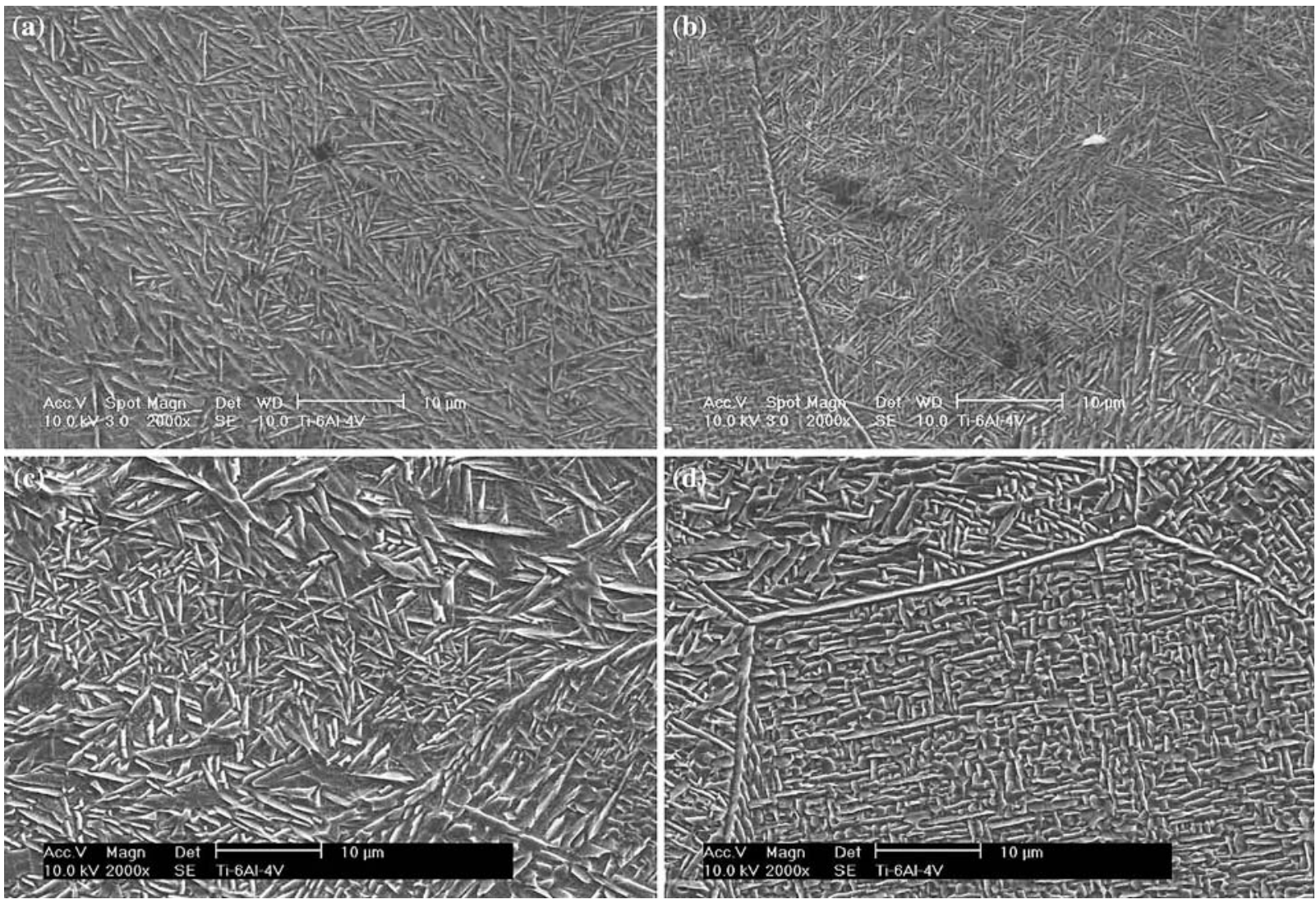

Fig. 7-SEM micrographs of as-deposited Ti-6Al-4V scaffold: $(a)$ through $(c)$ basketweave Widmanstätten $\alpha$ and $(d)$ near equiaxed-like morphology with a smaller aspect ratio of $\alpha$ laths.

several dislocations were observed in the alpha laths. Moreover, careful TEM examination also showed that few (less than 1 pct) $\alpha$ laths contained parallel multiple twins (Figure $8(\mathrm{c})$ ). However, twinning is not expected in Widmanstätten $\alpha$ unless extreme deformation conditions are imposed (cryogenic temperature and shock loading). On the other hand, twinning was frequently observed in martensitic $\alpha^{\prime} .^{[12,17]}$ Hence, TEM investigation revealed that a small fraction of martensitic $\alpha^{\prime}$ might be present in the as-deposited sample. However, no clear martensitic structure was observed in the SEM investigation.

\section{Mechanical Properties}

A tensile test was performed in order to study the mechanical properties of the laser-deposited scaffold. For the medical implants, the scaffold should have 

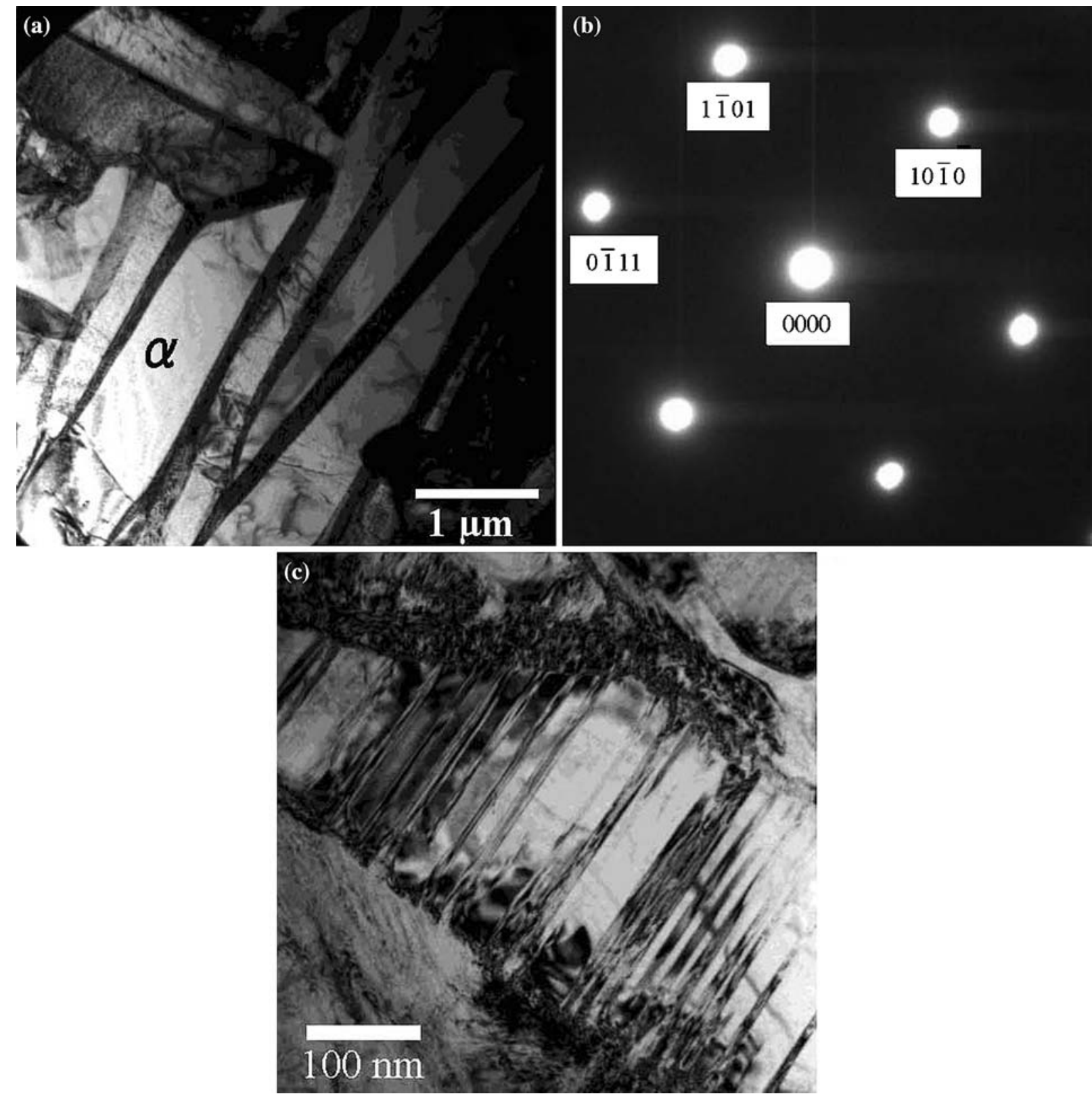

Fig. 8-TEM micrographs of the as-deposited Ti-6Al-4V: $(a)$ bright-field image showing Widmanstätten $\alpha$ with high density of dislocations, $(b)$ selected area diffraction pattern of image (a) $\left\{\mathrm{ZA}=[\overline{1} 2 \overline{1} 3]_{\alpha}\right\}$, and (c) parallel twins.

sufficient mechanical strength, which should be more than that of living bone. Figure 9(a) shows the stressstrain curve of the laser-deposited Ti-6Al-4V after different heat treatments. The tensile test results are also shown in Table II. It can be seen from Figure 9(a) and Table II that the tensile and yield strengths of the as-deposited Ti-6Al-4V were $1163 \pm 22$ and $1105 \pm 19 \mathrm{MPa}$, respectively, which are quite higher than the ASTM limits (896 and $827 \mathrm{MPa}$ ) for Ti-6Al-4V implants. ${ }^{[12]}$ However, the ductility (the breaking elongation) of the as-deposited sample was very low ( $\sim 4 \mathrm{pct})$, which is well below the ASTM limit (10 pct). In order to improve the ductility, the laser-deposited samples were annealed at $950{ }^{\circ} \mathrm{C}$ and $1050{ }^{\circ} \mathrm{C}$ for 1 hour followed by either AC or FC. The best combination of strength and ductility were found in the sample annealed at $950{ }^{\circ} \mathrm{C}$ followed by furnace cooling. Both strength (UTS $1045 \pm 16$ and YS $959 \pm$ $12 \mathrm{MPa})$ and ductility $(\sim 10.5 \pm 1 \mathrm{pct})$ of the furnace cooled samples were higher than the ASTM limits. It should be noted that the sample annealed at $1050{ }^{\circ} \mathrm{C}$ showed lower strength and ductility compared to the sample annealed at $950{ }^{\circ} \mathrm{C}$. The observed difference of tensile properties of different heat-treated samples can be explained with the corresponding microstructure of the sample. Figures 9(b) through (f) show the SEM micrographs of as-deposited Ti-6Al-4V after different heat treatments. The most common observation of the as-deposited and additionally heat-treated samples is that all microstructure were Widmanstätten in nature. 

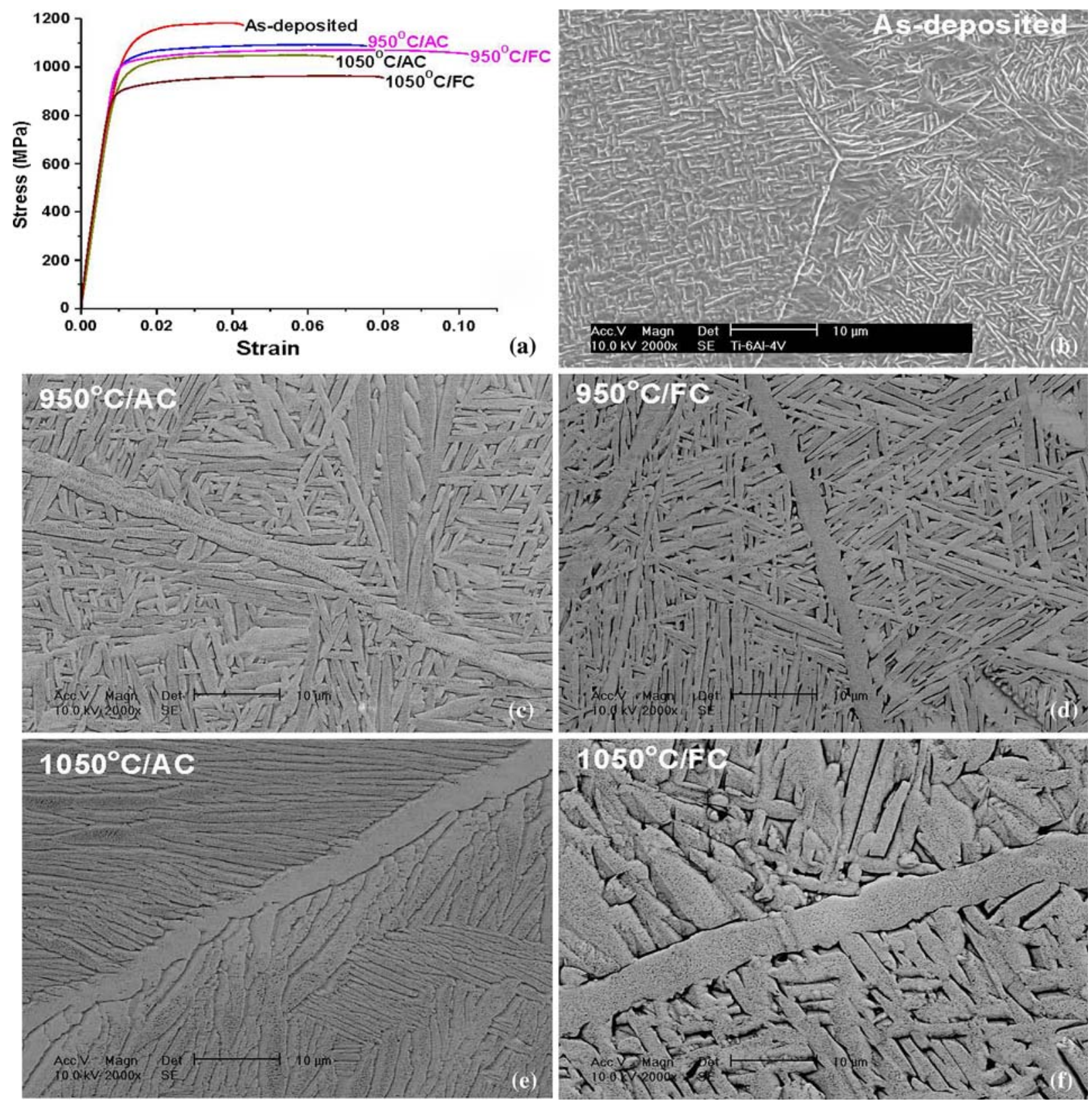

Fig. 9-(a) Stress-strain curves of the laser-deposited Ti-6Al-4V after different heat treatments. SEM micrographs of Ti-6Al-4V scaffold: (b) as-deposited, $(c)$ annealed at $950{ }^{\circ} \mathrm{C}$ followed by AC, $(d)$ annealed at $950{ }^{\circ} \mathrm{C}$ followed by $\mathrm{FC},(e)$ annealed at $1050{ }^{\circ} \mathrm{C}$ followed by $\mathrm{AC}$, and (f) annealed at $1050^{\circ} \mathrm{C}$ followed by FC.

Table II. Tensile Properties of Direct Metal Deposited Ti-6Al-4V after Different Heat Treatments

\begin{tabular}{lrrr}
\hline & $\begin{array}{c}\text { Yield Strength } \\
(\mathrm{MPa})\end{array}$ & $\begin{array}{c}\text { Ultimate } \\
\text { Strength } \\
(\mathrm{MPa})\end{array}$ & \multicolumn{1}{c}{$\begin{array}{c}\text { Pct } \\
\text { Elongation }\end{array}$} \\
\hline Heat Treatment & $1105 \pm 19$ & $1163 \pm 22$ & $4 \pm 1$ \\
As-deposited & $975 \pm 15$ & $1053 \pm 18$ & $7.5 \pm 1$ \\
$950^{\circ} \mathrm{C} /$ air cool & $959 \pm 12$ & $1045 \pm 16$ & $10.5 \pm 1$ \\
$950^{\circ} \mathrm{C} /$ furnace cool & $931 \pm 16$ & $1002 \pm 19$ & $6.5 \pm 1$ \\
$1050{ }^{\circ} \mathrm{C} /$ air cool & $900 \pm 14$ & $951 \pm 15$ & $7.5 \pm 1$ \\
$1050{ }^{\circ} \mathrm{C}$ /furnace cool & $900 \pm 14$ \\
\hline
\end{tabular}

In addition, the prior $\beta$ grain boundaries are decorated with $\alpha$. Moreover, the thickness of grain boundary $\alpha$ is higher as the annealing temperature is higher, being $\sim 0.7 \mu \mathrm{m}$ of as-deposited sample, $\sim 2.5 \mu \mathrm{m}$ at $950{ }^{\circ} \mathrm{C} / \mathrm{AC}$, $\sim 2.7 \mu \mathrm{m}$ at $950{ }^{\circ} \mathrm{C} / \mathrm{FC}, \sim 3.8 \mu \mathrm{m}$ at $1050{ }^{\circ} \mathrm{C} / \mathrm{AC}$, and $\sim 4.7 \mu \mathrm{m}$ at $1050{ }^{\circ} \mathrm{C} / \mathrm{FC}$ samples. The higher strength and lower ductility of the as-deposited sample may be explained in terms of very fine microstructure $(\alpha, \beta)$ of the sample. However, the as-deposited sample shows a ductile fracture surface with classical dimple morphology (Figure 10). The annealed samples show better ductility due to the coarse and uniform microstructure. In contrast, the sample annealed at $1050{ }^{\circ} \mathrm{C}$ showed lower ductility because of the thicker grain boundary $\alpha$ compared to the sample annealed at $950{ }^{\circ} \mathrm{C}$. It was found in the optical micrograph (Figure 6(a)) that the axes of the prior $\beta$ grain, which is columnar in nature, 


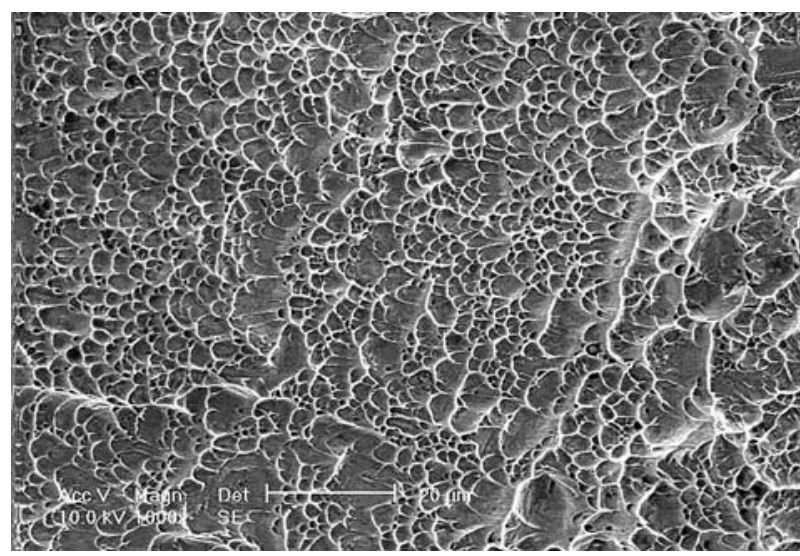

Fig. 10-Tensile fracture surfaces of the as-deposited Ti-6Al-4V shows a ductile fracture surface.

are parallel to the build direction. Hence, during tension testing, the grain boundary $\alpha$ was subjected to a tensile stress, because the tensile axis of the specimen was perpendicular to the deposit direction. Therefore, under tensile stress, cracks can easily propagate along the grain boundary and thicker grain boundary $\alpha$ enhanced the propagation of cracks along the grain boundary.

\section{DISCUSSION}

According to the Ti-V phase diagram at 6 wt pet $\mathrm{Al}$ (Figure 11), the Ti-6Al-4V exhibits a microstructure consisting of a mixture of $\alpha$ (hcp) and $\beta$ (bcc) phases at room temperature, whereas single-phase $\beta$ is stable above $1000{ }^{\circ} \mathrm{C}$. However, the room-temperature microstructure varies based on the thermal history of the alloy. For example, the cooling rate from the $\beta$-phase region to a temperature significantly below the $\beta$ transus defines the nature of the $\alpha$ phase, whether it will be martensite or diffusion-controlled Widmastätten structure. ${ }^{[13]}$ Heat treatments can be used to alter the distribution, size, and morphology of the $\alpha$ phase, but generally do not have a large effect on the prior- $\beta$ grains.

An optical micrograph (Figure 6(a)) shows that prior $\beta$ grains are columnar in nature, whose axis is approximately parallel to the $Z$-axis, i.e., the build direction of the deposit. During laser deposition, cooling of a molten pool occurs mostly via the substrate and via the surrounding atmosphere. Heat loss through the substrate leads to more rapid cooling via the substrate than through convection and radiation. This leads to directional growth of the grains counter to the cooling direction and, subsequently, to the formation of columnar grains. The maximum height of the individual deposited layer is around $0.3 \mathrm{~mm}$. However, we found that the length of columnar grains varies from 5 to $15 \mathrm{~mm}$. Therefore, the columnar grains, nucleated at the first deposited layer, were continuously grown during deposition of the following layers. Recently, several researchers have also reported similar microstructural observation of laser-deposited Ti-6Al-4V..$^{[15-17]}$

It is very difficult to predict the microstructure of the DMD sample because of its very complex thermal

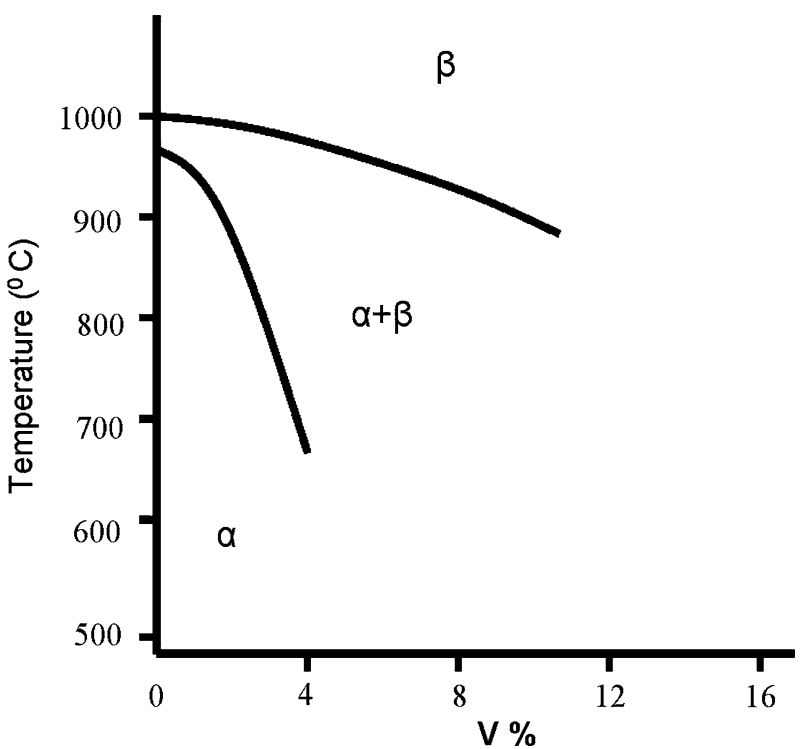

Fig. $11-$ Corner of Ti-V phase diagram at 6 wt pet Al.

history. Recently, Qian et al. ${ }^{[14]}$ have developed a finite element model for temperature history prediction in direct laser deposition samples. According to their model, during laser deposition, the very top layer cools from the liquid at a rate of $\sim 7 \times 10^{4} \mathrm{~K} \mathrm{~s}^{-1}$ directly to a temperature significantly below the martensite start temperature. Ahmed et al. ${ }^{[13]}$ have shown that Ti-6Al$4 \mathrm{~V}$ completely transformed to the martensitic structure at the cooling rate above $410 \mathrm{~K} \mathrm{~s}^{-1}$. However, in the present study, no clear martensitic microstructure was observed even at the topmost layer of the as-deposited sample. Thus, it should be noted that the cooling rate of the present deposition process was less than $410 \mathrm{~K} \mathrm{~s}^{-1}$. The SEM investigation revealed that the as-deposited microstructure is mainly various morphological forms of diffusion-controlled $\alpha$. The observed microstructure is mostly a mixture of coarse and fine $\alpha$ laths. The observed microstructural difference at different locations of the sample can be explained in terms of the complex thermal history of the as-deposited sample. During DMD processing, the temperature of the pre-existing layers can exceed the $\beta$ transus $\left(\sim 1000^{\circ} \mathrm{C}\right)$ during the deposition of subsequent layers. As a result, a new heataffected zone formed locally in the deposit every time the laser passed. This thermal excursion could result in coarsening of primary $\alpha$ laths, as found in Figure 9. Hence, the fine $\alpha$ laths are probably a result of the rapid cooling of the laser-deposited layer during the initial deposition process, whereas coarse $\alpha$ laths are a result of diffusion-controlled growth of the $\alpha$ laths during thermal excursion, with an additional layer added to the preexisting layer.

\section{CONCLUSIONS}

The Ti-6Al-4V scaffold for the porcine CRU bone tissue engineering has been successfully fabricated by 
DMD technology. It should be noted that the additional treatment including annealing and sandblasting was necessary in order to meet essential mechanical and surface criteria recommended for bone tissue engineering. The ductility of the as-deposited tensile sample was below the ASTM limit for Ti-6Al-4V implants. After a suitable heat treatment (sample annealed at $950{ }^{\circ} \mathrm{C}$ followed by furnace cooling), both strength (UTS $1045 \pm 16, \mathrm{YS} \sim 959 \pm 12 \mathrm{MPa})$ and ductility $(\sim 10.5 \pm$ 1 pct) become higher than ASTM limits for medical implants.

\section{ACKNOWLEDGMENTS}

This work was supported by the Army Tank Command R\&D group via Allion Corporation. Todd Richman was the program manager.

\section{OPEN ACCESS}

This article is distributed under the terms of the Creative Commons Attribution Noncommercial License which permits any noncommercial use, distribution, and reproduction in any medium, provided the original author(s) and source are credited.

\section{REFERENCES}

1. K. Wang: Mater. Sci. Eng. A, 1996, vol. 213, pp. 134-37.

2. Y. Zhang and M. Zhang: J. Biomed. Mater. Res., 2001, vol. 55, pp. 304-12.
3. A.S. Goldstein, T.M. Juarez, C.D. Helmke, M.C. Gustin, and A.G. Mikos: Biomaterials, 2001, vol. 22, pp. 1279-88.

4. J.L. Koch and J. Mazumder: Proc. ICALEO, Laser Institute of America, Orlando, FL, 1993, pp. 556-65.

5. J. Mazumder, J.D. Dutta, N. Kikuchi, and A. Ghosh: Opt. Las. Eng., 2000, vol. 34, pp. 397-414.

6. R. Mah: Adv. Mater. Process., 1997, vol. 151, pp. 31-33.

7. G.K. Lewis, R. Nemec, J. Milewski, D.J. Thoma, D. Cremers, and M. Barbe: Proc. Int. Congr. on Applications of Lasers and ElectroOptics, Laser Institute of America, Orlando, FL, 1994, pp. 17-26.

8. D.M. Keicher, W.D. Miller, J.E. Smugeresky, and J.A. Romero: Proc. TMS Annual Meeting, San Antonio, TX, ASM INTERNATIONAL, Materials Park, OH, 1998, pp. 369-77.

9. D.M. Keicher and W.D. Miller: Met. Powder Rep., 1998, vol. 53, pp. 26-28.

10. J.L. Koch and J. Mazumder: U.S. Patent Number 6,122,564, Sept. 2000.

11. C.L. Flanagan, S.J. Hollister, G.P. Dinda, and J. Mazumder: unpublished research.

12. Annual Book of ASTM Standards, Medical Devices, ASTM Standard No. F136-79, Section 13, ASTM International, West Conshohocken, PA, 1983, vol. 13.01, pp. 29-31.

13. T. Ahmed and H. Rack: Mater. Sci. Eng. A, 1998, vol. 243, pp. 206-11.

14. L. Qian, J. Mei, J. Liang, and X. Wu: Mater. Sci. Technol., 2005, vol. 21, pp. 597-605.

15. P.A. Kobryn, E.H. Moore, and S.L. Semiatin: Scripta Mater., 2000, vol. 43, pp. 299-305.

16. X. Wu, J. Liang, J. Mei, C. Mitchell, P.S. Goodwin, and W. Voice: Mater. Des., 2004, vol. 25, pp. 137-44.

17. S.M. Kelly and S.L. Kampe: Metall. Mater. Trans. A, 2004, vol. 35A, pp. 1861-67.

18. F.J. Gil, J.M. Manero, M.P. Ginebra, and J.A. Planell: Mater. Sci. Eng. A, 2003, vol. 349, pp. 150-55. 